\title{
Short horizons and obesity futures: Disjunctures between public health interventions and everyday temporalities
}

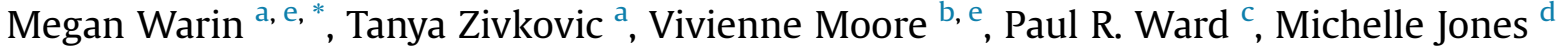 \\ a Department of Gender Studies and Social Analysis, School of Social Sciences, Napier Building, University of Adelaide, Adelaide, South Australia 5005, \\ Australia \\ ${ }^{\mathrm{b}}$ Life Course \& Intergenerational Health Research Group, Discipline of Public Health, School of Population Health \& Clinical Practice, University of Adelaide, \\ Adelaide, South Australia 5005, Australia \\ ${ }^{\mathrm{c}}$ Discipline of Public Health, School of Health Sciences, Flinders University, GPO Box 2100, Adelaide, 5001 South Australia, Australia \\ d Department for Health and Ageing, Government of South Australia, PO Box 287 Rundle Mall, Adelaide 5000, Australia \\ e The Fay Gale Centre for Research on Gender, University of Adelaide, Australia
}

\section{A R T I C L E I N F O}

\section{Article history:}

Available online 17 January 2015

\section{Keywords:}

Australia

Obesity

Public health prevention

Temporality

Bourdieu

Future

Disadvantage

\begin{abstract}
A B S T R A C T
This paper examines the spatio-temporal disjuncture between 'the future' in public health obesity initiatives and the embodied reality of eating. Drawing upon ethnographic fieldwork in a disadvantaged community in South Australia (August 2012-July 2014), we argue that the future oriented discourses of managing risk employed in obesity prevention programs have limited relevance to the immediacy of poverty, contingencies and survival that mark people's day to day lives. Extending Bourdieu's position that temporality is a central feature of practice, we develop the concept of short horizons to offer a theoretical framework to articulate the tensions between public health imperatives of healthy eating, and local 'tastes of necessity'. Research undertaken at the time of Australia's largest obesity prevention program (OPAL) demonstrates that pre-emptive and risk-based approaches to health can fail to resonate when the future is not within easy reach. Considering the lack of evidence for success of obesity prevention programs, over-reliance on appeals to 'the future' may be a major challenge to the design, operationalisation and success of interventions. Attention to local rather than future horizons reveals a range of innovative strategies around everyday food and eating practices, and these capabilities need to be understood and supported in the delivery of obesity interventions. We argue, therefore, that public health initiatives should be located in the dynamics of a living present, tailored to the particular, localised spatio-temporal perspectives and material circumstances in which people live.
\end{abstract}

(c) 2015 Elsevier Ltd. All rights reserved.

\section{Introduction}

In Australia (as in many countries) public health campaigns that focus on obesity prevention and intervention employ a taken-forgranted concept of 'the future'. Obesity discourses are replete with time metaphors in which looking to the future and developing foresight is thought to mitigate risk. Obesity is repeatedly described as a 'time crunch' (Barry et al., 2009), a 'time bomb' and as a 'threat to the future' (Evans, 2010); a risk factor for future illnesses such as diabetes and coronary heart disease. Diprose (2008), building upon

\footnotetext{
* Corresponding author. Department of Gender Studies and Social Analysis, School of Social Sciences, Napier Building, University of Adelaide, Adelaide, South Australia 5005, Australia.

E-mail address: megan.warin@adelaide.edu.au (M. Warin).
}

Beck's (1992) concept of 'risk society', suggests that this 'comportment towards the future' draws together both calculable and newer, incalculable modes into an intensified paradigm of preemption.

Ewald (1991) suggests that 'nothing in itself is a risk; there is no risk in reality. But on the other hand, anything can be a risk; it all depends on how one analyses the danger, considers the event' (1991, p. 199). Risk is a way of ordering social imaginaries, and while the future of 'lifestyle problems' like obesity is uncertain, a perception of future dangers is required through the construction of calculable practices. As a phenomenon, obesity is thus assessed and calculated, producing probabilities for interventions in the present (Adams et al., 2009). For example, Australia's National Preventative Health Taskforce states that: 
Based on current trends there is an urgent and immediate need to address the growing prevalence of obesity and overweight in Australia. The most recent projections from Access Economics, assuming a constant increase in obesity prevalence over the next 20 years in line with current trends, estimate that there will be 6.9 million obese Australians by 2025 (2009, p. 9).

While Bauman (2006) questions such calculability of future risks in what he refers to as 'liquid society', he notes that speculative forecasting sets in train an overall effect of action - 'a necessity to act, to plan actions, to calculate the expected gains and losses of the actions, and to evaluate their outcomes' (Bauman, 2007, p. 4). It is the cycle of fear and action that demands precaution and preparedness for the future by taking action in the present. In this 'characteristic state of anticipation' (Adams et al., 2009), fatness can thus be anticipated (Evans, 2010) and even feared, and citizens are urged to act and optimise their health for the best possible future (Adams et al., 2009).

Australia's first nation-wide mass media campaign on obesity in 2008 (Measure up - www.measureup.gov.au) is an exemplar of this cyclical, pre-emptive paradigm. The campaign depicts a young man (and in a separate advertisement a young woman) walking on an oversized tape measure, getting fatter and older as he gets closer to the viewer. His daughter appears at different life stages, but as he ages he is too fat and too unfit to play with her. A follow up advertisement sees the same man 'taking control' of his behaviours and walking back along the measuring tape away from the viewer, losing weight around his waist and eating an apple (see also Lupton, 2014). Temporality in this campaign is simply presented as linear, decontexualised life course with an ability to foresee the future and to take prudent action to mitigate any possible risks. In their evaluation of the 'Measure up' campaign in New South Wales (Australia), King et al. (2013) note that awareness of the campaign was higher among more educated and affluent adults (2013, p. 1036), suggesting that they may have an ability to imagine and plan their futures and take pre-emptive action (as the campaign depicted). Bourdieu (2000) argues that the power to control the future 'means first of all having a grasp on the present itself' (2000, p. 221). What does the future mean for people living in disadvantaged circumstances who, as one participant said, are concerned with 'just getting through every day'? What futures might they imagine and do public health futures have universal relevance?

This paper seeks to answer these questions by taking the politics of temporality as a lens through which to examine the ways in which people in a disadvantaged Australian community respond to Australia's largest childhood obesity prevention program. The first section of the paper describes the methodological approach of the study and the program. The Obesity Prevention and Lifestyle Program (OPAL) began in 2009 in a South Australian community that is known for significant social and economic disadvantage, including high rates of obesity (Hordacre et al., 2013). Importantly for this analysis, the focus of OPAL is explicitly on increasing the proportion of children aged $0-18$ years in a healthy weight range. While Olds et al. (2010) has suggested that obesity amongst children has recently plateaued in Australia, it remains at a high level and continues to be a focus. As Evans (2010) notes, focussing on children is key to the pre-emptive paradigm as childhood 'becomes unproblematically associated with the future, because of the affective power of childhood to provoke hope (and by equal measure, fear and tragic loss)' (Kraftl, 2008, p. 84, cited in Evans, 2010). Children are seen to represent the future generations of obese adults (Zivkovic et al., 2010), and childhood is where much of the effort to fight fatness is located (Coveney, 2008, p. 203).

Extending Bourdieu's temporal orientations to practice, we develop the concept of short horizons to articulate the narrowed vistas of possibility and the improvisational practices that clearly circumscribed participants' abilities to respond to OPAL messages. We examine how 'biographies of disadvantage' (Graham et al., 2006) impact on experiences of time; how phenomenological dimensions of future time (fatalistic and often unimaginable) are discordant with the synoptic time of public health futures. It is not that people do not have hopes or aspirations for the future but rather that they are shaped by the reality of the present and may be limited and situational.

The final section details how participants are able to create alternative futures, and how improvisational practices create innovations and necessities that bring about living presents (Anderson, 2010) - of opportunities to do and to manage with what is in reach. In conclusion we suggest that there are different dimensions of time beyond the public health progression of linear and catastrophic futures that need to be considered in public health obesity interventions in disadvantaged communities.

\section{A 'city for tomorrow'}

The location of this ethnographic study is an area that was developed in the outer regions of Adelaide in the 1950s. It was marketed as the 'City for Tomorrow', a picture postcard place named after Queen Elizabeth II with aspirations for upward social mobility and material security. Brand new affordable housing, wide suburban spaces, and secure employment through the local car industry attracted many UK working class migrants. This new life offered people opportunities to 'build their futures' and 'breathing room' to keep their children in school or get them into good trades, even to take an occasional holiday (Peel, 1995, p. 119). In the 1960s and 1970s more and more working class UK migrant families could enact the hope that brought them to places like Elizabeth. This optimism continued to the 1980s until the entry into the market of cheaper, imported cars, and an economic downturn meant Elizabeth faced an 'uncertain future' (Peel, 1995, p. 156).

Despite significant investment into urban regeneration projects and initiatives in Elizabeth and surrounding suburbs, what was labelled as the City for Tomorrow in government brochures of the 1960s, today remains a place that has pockets of 'deep and persistent disadvantage' (McLachlan et al., 2013). According to the Australian Bureau of Statistics (ABS) Socio-Economic Index for Areas (SEIFA), Elizabeth is Adelaide's most disadvantaged area (ABS, 2013) and has the country's second highest youth unemployment rate of $41 \%$. Households are characterized by low incomes, a high prevalence of sole parent families, and in one council area $77 \%$ of children live in low income families (Hetzel et al., 2004). While some participants in our study spoke of a strong community pride that comes from facing persistent hardship and austerity, others frequently acknowledged the many social problems (domestic violence, unemployment, food insecurity and mental illness) that have become embedded across generations and need to be faced on a day to day basis.

\section{Methodology and methods}

It is widely acknowledged that obesity is socially patterned according to socio-economic status (Sobal and Stunkard, 1989; Ball and Crawford, 2006; McLaren, 2007). From January 2011 to December 2013 the proportion of South Australian adults who selfreported being overweight and obese was 59.7 per cent, while 70.7 per cent of adults living in Playford (the council area in which Elizabeth is situated) self-reported being overweight and obese (The University of Adelaide, 2014). Factors that contribute to higher levels of obesity amongst disadvantaged populations in Australia 
include a range of structural determinants - poverty, rising food prices in Australia, greater density of unhealthy food options in low SES areas, employment status, financial obligations, single parent and rental households, those identifying as Aboriginal and Torres Strait Islander, recently arrived refugees and lack of access to private transport (Law et al., 2011, p. 456). When sites were selected for the rolling out of Australia's largest obesity prevention initiative, levels of childhood obesity and disadvantage were considered. Based on need, the City of Playford was one of the first locations where OPAL began in 2009.

Ethnographic research methods of participant observation, indepth interviews and engagement in community life were employed to explore taken-for-granted understandings of food, bodies and activity, and to identify whether obesity interventions might encounter strong cultural resistance to social change. Data collection occurred over a period of twenty three months (August 2012-July 2014), in which one researcher was located in the broader community and at a food bank location, and another researcher conducted the majority of face-to-face interviews with 37 families and 10 stakeholders (including community workers, local government employees and State government managers). Ethics approval for the project was sought and given by The University of Adelaide Human Ethics Research Committee (No: 2012102); Southern Adelaide Clinical Human Research Ethics Committee/Department of Health (No: 12-SAH-45); and the Aboriginal Health Council Ethics Committee (No: 04-12-489).

Interviewees (aged 16-65) were purposively selected and recruited through community noticeboards and snowball sampling, and were offered an honorarium of an AUS \$40 voucher. Inclusion criteria comprised households with a range of family configurations (single parent, dual income, unemployed, Indigenous) to provide a sample that reflected the diversity of families in the research site. Seven interviewees identified as Indigenous Australians, and the majority of all interviewed were women and dependent on government benefits. As 'family' is a socially constructed category we included those households that identified as families, but may not have had children (e.g. same sex couples). This was a difficult sample to recruit as there is a level of stigma associated with 'being from Elizabeth' (City of Playford, 2004, p. 9) and discussions about obesity and 'proper' nutrition are morally loaded (Warin and Gunson, 2013). One of the researchers grew up in the area, and was perceived by some community members as 'an insider', helping her to gain access to a wide range of community services and people.

A semi-structured interview schedule was used with family and stakeholder participants. Families were asked to describe what things were important in their lives, what gave them a sense of well-being, if they worried about their health and what their lives might look like in five to ten years time. Stakeholders were asked about the challenges to implementing interventions in this community and asked to provide examples of how OPAL messages had been taken up in the everyday lives of families in Playford.

As participating and observing in everyday family life entailed being in the various places where children and families gathered, research was carried out in people's homes and in public spaces on buses and trains, in community centres, shops and neighbourhood streets. All participant observations were typed into a laptop and de-identified via pseudonyms in the process. Participant observation included hand written drawings and photographs of places, taking note of where objects and people were positioned, and the sensory dimensions of locations. Family and stakeholder interviews lasted between $30 \mathrm{~min}$ and $3 \mathrm{~h}$ and were digitally recorded and transcribed by a professional transcriber, and for accuracy checked by members of the research team.

Analysis of all data occurred thematically through key stages of familiarization, identifying a thematic framework, manual coding of transcripts and field notes, mapping and interpretation via social theory (Ezzy, 2002). Triangulation of the data was achieved through independent code checking between the researchers. As with all ethnographic data the sample does not claim to be representative, and the sampling may be shaped by the offer of a reimbursement which could have attracted people in the community with severely limited income. One respondent was declined due to the difficulty of ascertaining where he lived (he was visiting from outside of the council area) and who he lived with.

\section{Public health and synoptic time}

The OPAL program is a community-based childhood obesity prevention initiative that aims to improve the eating and activity patterns of children. The program is modelled on the French EPODE initiative (Hartwick et al., 2014) and is based on a three pronged approach of social ecological theory, community development and social marketing (Williams and Weir, 2013). OPAL attempts to work in and with communities, and has close partnerships with local councils, businesses and community groups. Goals to change individual behaviours (such as replacing soft drink consumption with water, encouraging children to ride to school, turn the television off and play outside) are admirable, and there is clear focus on envisaging and supporting 'long term' goals of improving healthy weights amongst children.

While OPAL prefers to downplay the use of the word obesity in its local events and social marketing products (despite the word 'obesity' being in its title), it is embedded in public health frames of temporality which take for granted that people should look to the future and thus be motivated to mitigate future risks associated with obesity. OPAL seeks to manage a potentially threatening obesogenic environment by creating conditions in which community members can internalise and act in accordance with shared moral norms about the future benefits of healthy lifestyles (Carter et al., 2011, p. 57-58). When we asked Candy, an unemployed single parent of an 18 year old daughter, 'Do you tend to think about the future?' She responded, 'Not really. I haven't really thought about it.' And when asked, 'What do you think the future might look like for you?' she hesitated not knowing how to answer the question before finally revealing, 'I don't know because I don't know what I'm going to be doing. Life's always changing, anything could happen.'

Bourdieu's work on the attitudes towards time of Algerian peasants (1963) and chronically unemployed people living in the US and Paris (1999) alerts us to sets of assumptions concerning time. He articulates the variation between the quantifiable, objective time of the clock or 'time-as-thing' and subjectively experienced time or time as practiced, which is the everyday common temporal experience as we go about our lives (Bourdieu, 2000).

Bourdieu argues that there are all sorts of cognitive devices (metaphor and analogy being examples) which help to structure our knowledge of the world and its spatio-temporal orientations (Jenkins, 2002, p. 56). He suggests that synopsis is the most common way in which complex information can be simplified and condensed into a single frame of reference. He calls this the synoptic illusion. Bourdieu critiques anthropology for the way in which diagrams, genealogies and calendars substitute a linear, homogenous time for practical time, which is made up of incommensurate islands of duration, each with its own rhythm, the time that flies by or drags, depending on what one is doing (Bourdieu, 1977, p. 105).

Many public health programs similarly take a view of time as linear, homogenous and continually future orientated, as if 'temporality itself is not really open - the future is already foretold' (Evans, 2010, p. 23). Like many other obesity prevention 
interventions OPAL has a particular focus on children, as they embody the future. The need for this program in this location was based on evidence of one in five 4-year-old children being overweight or obese. Future risk is thus drawn in: 'Overweight children are very likely to become overweight adults; with a greatly increased risk of heart disease, type-2 diabetes and other chronic problems' (http://www.playford.sa.gov.au/page.aspx?u=1745). This vision of the future is designed to act as a catalyst for anticipatory action (Evans, 2010, p. 26), in which 'affective facts' (Massumi, 2010, p. 54) legitimise and mobilise fear. This preemptive discourse is similarly taken-for-granted in UK policy documents on obesity (see Evans, 2010) and the raison d'etre of OPAL, assuming that every body shares a similar orientation towards the future and its implications for care of self and care of others.

However, this synoptic account of time that captures and fixes the future was often discordant with the 'everyday, embodied, here-and-now' (Dodghson, 2008) realities of our participants. One participant, June, exemplifies this discordance. She is an obese grandmother with diabetes who lives on her own in public housing and survives on a government unemployment benefit. Receiving this limited income is dependent on participation in the Australian government policy of 'mutual obligation' (Parliament of Australia, 2004). In June's case, this includes her participation in part-time study and working in a voluntary capacity for up to $15 \mathrm{~h}$ a week. Often feeling physically exhausted, her weight and diabetic condition prevent her from walking even short distances and her income constrains the amount of fresh fruit, vegetables and meat she is able to eat on a regular basis. While doing her food shopping June buys a packet of discounted biscuits for dinner. She looks at the biscuits longingly and reveals that she 'can't wait to get home and relax', which will involve eating the packet of cheap biscuits, 'planting my backside on the sofa and switching on the television'. 'Ah, lovely' she says in anticipation of the pleasure. Regularly consuming high-fat and high-sugar content foods, June struggles to manage her blood sugar levels and often experiences hypoglycaemic episodes.

June is aware of health promotion advice about the impact of high-sugar and high-fat foods on weight and diabetes. Her 'dinner' of chocolate biscuits is visually depicted as a food to eat 'only sometimes and in small amounts' in the current Australian Guide to Healthy Eating (Australian Government, 2014). Like other food pyramids and tables, these government guidelines attempt to structure and simplify our knowledge of food and eating. Distinctions are made between different types of foods and the amount of each food type to be consumed is depicted in chart form. These guidelines also signify government objectives to prevent obesity and chronic disease. As a synoptic illusion, the Australian Guide to Healthy Eating simplifies complex information - what, when and how to eat - and assumes that the social context is transparent.

The synoptic character of the Australian Guide to Healthy Eating diagram foregrounds abstract temporalities but not the subjective practical sense of time that is experienced. It creates a coherent, structured, logically organised cultural form that does not fit with the everyday practical logic. It ignores the many social dynamics that are learnt in acquiring embodied knowledge about food and eating, including the skills, perceptions, memories and desires that food and the myriad of social relationships it crosses are charged with. Bourdieu argues that these synoptic simplifications do violence to time and space, condensing the multidimensional into two-dimensional form and failing to resonate with the 'playing out of strategies in practice' (Wight, 2006, p. 87), of how when the adverse circumstances of everyday life take their toll, high-sugar convenience foods can sweeten the moment (Zivkovic et al., 2015).

Obesity interventions have a 'dynamics of expectation' (Brown and Michael, 2003) that is intensely future orientated, but June's temporal situatedness is firmly rooted in a particular time and place. OPAL wants to challenge the time crunch of obesity, and in thinking of how to act in the present to bring children into the healthy weight range in the future, OPAL asks children, parents and carers to make time for exercise (scoot to school), to make time for breakfast, and to do different things with their time (play outside, engage in more 'home cooking'). But as June demonstrates, time is not 'a neutral temporal space into which objective expectations can be projected' (Brown and Michael, 2003, p. 4). Time is an analytical category, and firmly embedded in and experienced differently according to one's habitus.

\section{The future and practical time}

For the people in our project, outlooks on the future are inscribed in their immediate present and pasts, in their habitus. Participants could articulate an imagined picture of the future for themselves, however these futures were situated in uncertain and contingent 'living presents' (Anderson, 2010, p. 793). Economic capital through financial security (rather than healthy bodies) was more often presented as a necessary pre-condition for participants to be able to realistically envision their future, but this was often severely constrained.

The most striking evocation of the lack of urgency concerning pre-emptive action was shown by Ellie, a socially isolated, unemployed 63 year old woman:

Life's tough. A couple of months ago my doctor diagnosed me with Chronic Obstructive Pulmonary Disease. I lose my breath if I do anything quickly. It's the cigarettes. My doctor says I'd live another 5 years if I gave up smoking.

Ellie shrugs her shoulders and huffs - 'Pah! Another five years! I don't really know if I'd want that. Another five years. Of this?' A weary expression creeps across her face and she says:

But you know I could do with a bit more money, so I've cut down. I worked it out. You see I buy packets of 40 and each cigarette is a little more than 50 cents so by smoking 8 cigarettes less a day I'm saving \$4. It all adds up. But why would I stop? Really, what do I have in my life? Nothing. This is my only pleasure in life.

Ellie communicated her efforts to reduce the amount of cigarettes she smoked in financial terms; however, money saved is not something she could count on in the future, it is more of an immediate reward. 'The thing is' Ellie explained, 'I really don't want to count on that money from week to week because I don't know if I can continue to cut out those cigarettes'. For Ellie, the future comprises of unknowable and unanticipated happenings, any of which could potentially entice her to lighten the moment and smoke more. When the future looks bleak and you have limited economic capital to convert to other forms of capital, the rationing of momentary pleasures (like cigarettes, alcohol and food) limits opportunities to disrupt the dragging of time with enjoyment in the present.

Futures were rarely couched in terms of health or obesity. Pearl, aged 55, says 'fat is more visible in Playford. Here, there is [sic] just more open people. They don't spend their years trying to hide for the rest of their lives when they get a few bags [of extra flesh]'. For others the future was characterised as 'absolutely terrifying', given over to 'chance', 'luck' or 'fate'. When asked specifically about the future a grandmother in her 50s who cares for her pre-school 
grandson stated that it was 'unrealistic to think about the future'. Similarly, a young mother with 2 children and a significant history of mental illness and drug and alcohol issues responded: 'there is no future - I'm too busy coping with everyday things'.

The future was 'the here and now', 'one day at a time', or 'today and tomorrow and next week'. Atkinson (2013) reports a similar response by those living precarious lives in the UK, describing 'a sort of adaptive presentism' (2013, p. 655) in which aspirations are 'left open, uncertain and empty of intention' (ibid). As Bourdieu argues, time is a practice that depends closely on the objective potentialities which are defined for each individual by his or her social status and the material conditions of existence (Bourdieu, 1979, p. 53). So what is to be done (riding to school, walking the dog, using a fridge to prolong the life of foods) is defined in the relationship between the structure of expectations constitutive of a particular habitus, and the structure of possibilities, which is constitutive of a given social space (a social field) (Adkins, 2011, p. 535). These background expectations are 'socially powerful because they shape people's modes of perception, reflection and action, and, as a consequence, their spatio-temporally situated ways of relating to, making sense of, and acting upon the world' (Susen, 2013, p. 397).

What was defining in many people's background was traumatic pasts. In many ways, it was the past in which people conceived of the future. Interviews often began with unprompted narratives of time spoken through traumatic biographies, of domestic violence, regret and shame. As Fred, aged 25, said:

I focus on short term. I think I prefer to focus on [the] month ... so I look at things in a month and go 'oh, okay I can try to get that in a month' but I don't look that much into the future. I grew up on disappointment so I don't view the future as well as I should.

These entanglements of the past and the present resulted in revisions to OPAL social marketing material on Parks and places 'Life looks brighter outside', which initially asked parents to recreate their childhood. On advice from stakeholders, OPAL changed tack as this was not considered helpful for many families that have a past they would not want to recreate.

An ethnographic study from the Pacific island nation of Nauru makes a similar observation about culturally specific embodiments of time. Nauru has experienced rapid socio-economic and political changes since the 1970s, with concomitant rising rates of obesity. Islanders now have one of the highest obesity rates in the world (McLennan, 2013, p. 1). McLennan (2013) examines the effects of these rapid changes on everyday Nauruan lives, arguing that a new temporality of 'island time' imbues everyday social relationships and practice:

It means never planning too far ahead; this applies to life in general as well as to specific events. Ostensibly, it is about living for the moment, enjoying the here-and-now, and not worrying what the past held or what the future might bring. It is a counterpoint to being organised, risk averse, regretful about the past or stressed about the future. (McLennan, 2013, p. 104)

While this ethnographic location cannot be generalised to our Australian fieldwork site, the Nauruan perception of time has synergies with our findings. When people's lives are truncated due to a decline in socio-economic opportunities (and amidst other competing priorities), the capacity to plan for a future or promote the active avoidance of risk behaviours makes little sense.

Other studies exploring place and health have also noted how temporality is perceived according to different circumstances.
Johns' (2011) study on teenage motherhood and deprived environments in the UK found that young women engaged in future discounting and made short term future decisions. They were more likely to start sexual relationships at an early age and become mothers as they had negative views about their future and did not see long-term futures for themselves. These teenage girls perceived the world as a dangerous and unpredictable place and thought that their current situation was 'as good as it gets' - and this perception affected their temporal outlook. Graham $(1993,1994)$ in her study on smoking behaviour in Britain found that cigarette smoking was associated with women from low socioeconomic classes who have caring responsibilities and limited financial resources. Smoking punctuated the passing of time, it was a way of making time, of marking time. Returning to Ellie, who in conceiving the category of the future as an extension of her current predicament ('another five years of this'), experiences all temporalities in the embodied here and now (Dodghson, 2008). In all of these cases, responses to shortened horizons are rational and not necessarily conscious strategies to cope with living in an environment where there are fewer guarantees for experiencing a successful or healthy future (Johns, 2011, p. 129).

\section{Tastes of necessity}

Nowotny (1994, p. 11) argues that when it is difficult to anticipate future horizons 'the category of the future loses much of its attractiveness' and it is a challenge to engage in anticipatory ways of life. Agency then can be restricted when the anticipated, objective future is not within reach. But agency can however, be extended in improvisational and creative practices, which are rational responses in worlds where there may be few other opportunities to exert control. Our ethnographic research opens up new ways of imagining temporalities of health that do not necessarily prioritise 'the future'. This involves engaging with and understanding how our immediate present, our living present is a valuable temporal dimension of everyday lives.

One participant, Yvette, illustrated how she extends the present through meticulous attention to budgeting and food in her house. Self-described as the 'Jamie Oliver of Playford', Yvette lives on an extremely limited budget. She proudly opened her kitchen cupboards to reveal every inch of shelf space crammed with a wide range of foods (including long life products, cans of vegetables and packet mixes). On each cupboard door was a 'pantry stock' list, an inventory of food items which she purchases and updates from month to month. When she separated from her husband 15 years ago and raised two children on just $\$ 69$ a fortnight she learnt to 'live poor'. In learning to live poor she imagined that she lived in the time of the Great Depression, and as if any money or food she had could be her last. She said, 'You've got to think that you've got nothing ... It's called survival instinct.'

Living poor involves eating meat otherwise sold as dog-food at the butchers, and asking shop staff for packaged and canned foods that have passed their 'best before' dates. It also involves buying foods like pasta, rice and flour in bulk, growing vegetables and making a lot of food from scratch. These are not tastes of freedom, but tastes of necessity as the participant explains, "it was not a choice. It was, "Okay. I've got to survive. I've got two kids" ... You've got to concentrate on survival.' Yvette is reaching for material at hand and opening up temporal potentialities that are possible in her world.

Surviving on a limited income also presents challenges to eating in the share-house of 25 year old Fred who lives with and routinely cooks for other young unemployed men, practices which have earned him the title of 'house-mum'. Feeding a 'family' on a budget is a role with which Fred is intimately familiar and it is shaped by 
the cycles of paydays, oscillating between 'having nothing' in terms of meals to 'overcompensating' by providing 'extra' food to his household. As a young child Fred learnt to 'make little things go a long way' in cooking for a family of eight people with inadequate resources when his parents were 'on heroin' and unable to cook. Fred exclaims that it is 'important to have extra' and on paydays he will stock up on pasta, noodles, meat and vegetables, the staple and substantial foods used in his regular 'cook-ups'. 'Overcooking' and 'overeating' are a practical strategy used to offset scarcity by providing what one can in the present, and to nurture others by protecting them from hunger by 'overfeeding' them now.

These possibilities of what is at hand do not always accord with the future orientated synoptic time of health promotion, but fit with what is available and present in present time. Children in our study often remarked that they only eat breakfast cereal covered in sugar, and many said they did not like the taste of the bland cereal promoted by OPAL. Aged 5 and 6, two children were quick to express their disinterest in 'healthy breakfast' options saying they 'couldn't eat it like that. You need sugar.' One mother of five justified their stance, saying 'they're fussy the kids, they eat the cereals, you know, like Coco Pops and Nutrigrain'. When she gives her kids these sweet cereals she's able to buy herself time, 'five minutes of peace' in the mornings, literally and figuratively sweetening the moment and enabling her to manage her household and cope with its entailing stress. As Berlant (2011) argues, economic threats to families tend to produce households in 'which food is one of the few stress relievers' (2011, p. 116) and the eating of sweet foods provides a moment of comfort between children and parents. Framing the consumption of foods around a concern for future consequences fades away in the immediacy and moments of sensory pleasures and 'time out' for oneself.

\section{Conclusion and implications}

'Living poor' illustrates what is possible within the constraints of short horizons, the improvisations that people use in their day to day lives to deal with living presents, rather than anticipated futures. It is a practical realism about the future that is engendered by the reality of the present (Jenkins, 2002, p. 28). Importantly it involves a 'taste of necessity' in which survival - and not health - is the priority in many people's lives.

Anderson argues that 'anticipatory action is a key means through which life in contemporary liberal democracies is secured, conducted, disciplined and normalised' (2010, p. 792). This Foucauldian future orientation and governmentality is embedded in obesity intervention programs, which are often aimed at children and those who care for them, and seek to guide pre-emptive action. But the future is a temporo-spatial concept that is embodied and performed differently according to the materialities of its situatedness. In our research the future is not a simple linear trajectory but is conceived of and experienced in multiple ways: as the here and now, as disappointment, as hope, as unrealistic, as fatalistic, outside of one's control and as unimagineable.

The taken-for-granted concept of future in health promotion emphasises open and wide horizons in which one should acknowledge both the threats of the future (the time bomb metaphor) and the promise of what behaviour change can bring (better health). This is the model of calculating the future through obesity trends, and motivating people to take action and responsibility now to manage future risk. This is, however, only one way of relating to the future and fails to acknowledge alternative modes of temporality and their impact on health.

The arguments in this paper go beyond the literature on future discounting (see for example, Zhang and Rashad, 2008) which provide evidence on how obese women show greater delay discounting than healthy-weight women. The future discounting literature does not attend to 'the future' as an analytical category, inevitably raising questions that feed into common stereotypes about fat people's lack of control and self-will, and blaming them for their 'poor choices'. Similarly, promising work on designing interventions in obesity and 'delay discounting' (Daniel et al., 2013), does not attend to socio-economic dimensions of everyday lives, thus stripping behaviours to individual bodies, devoid of important social contexts.

Research that is attending to social class and its relation to obesity is beginning to point to the ways in which temporality and space are important to incorporate into obesity interventions. Spotswood and Tapp's (2010) case study on increasing physical activity in Scottish working class communities found that:

middle class people, with their wide horizons and confident choices from a vast range of activities, lifestyles and identities, contrasted starkly with our respondents from the deprived ward. Working class respondents' choices of possible activities was sharply limited by their habitus (2010, p. 54).

This does not mean, however, as Bourdieu himself suggests (2000), that the chronically unemployed or those who have no distance from necessity experience time as 'purposeless and meaningless' and are unable to create alternative futures (2000, p. 221-223). Our ethnographic data demonstrates that participants respond to their environment (and the capacities and strengths learnt and available in their habitus) through 'surviving' and 'living poor', which is far from the luxury of having an expansive array of opportunities and choices to hand.

Imaginings of the future for participants from situations of disadvantage reveal how temporal delineations knit together differently depending on one's habitus. Past, present and future are not distinct categories - personal histories (of family violence, substance abuse and poverty) persist in the present, shaping or constraining openings to other futures. Individual futures cannot be abstracted from these contexts, 'the pattern of which is determined by social forces and the relations of power in which we are all embedded' (Keane, 2006, p. 102). As Bourdieu notes, the experience of time 'depends on power and the [life] chances it opens' (Bourdieu, 2000, p. 223).

People in our study revealed that looking forward to the future - the pre-emptive basis that underpins obesity prevention programs - is inseparable from the obverse imagining, retrospection, attending to the past. Eating for pleasure and survival (and not for health) 'can be seen as a form of ballast against wearing out' (Berlant, 2011, p. 116), providing 'a sense of well-being that spreads out for a moment, not a projection toward a future' (ibid, p. 117). As suggested by Kumanyika et al., it is vital to identify localised community perspectives and material circumstances in which people live in order to paint a relevant and realistic picture of pathways for change in local contexts (Kumanyika et al., 2007). It is important that government policies aiming to extend the healthy lives of its citizens do not attend to a singular imperative of future bodily health but rather the present time (and its relationships to multiple temporalities) that orient the lifeworlds in which people dwell and obesity appears. This means not only attending to local meanings and experiences of temporality, but reflecting on how the dominant and internalised structures of 'the future' are taken-forgranted in public health campaigns and assumed to be a universal worldview (Kumanyika et al., 2012).

\section{Disclaimer}

The views expressed in this publication do not necessarily 
reflect South Australian Government Policies.

\section{Acknowledgements}

This project was funded by an Australian Research Council Grant (LP 120100155). South Australia Health (Government of South Australia) and the City of Playford have contributed funds and inkind support for this project. We wish to thank Dr Ruthie O'Reilly for assistance with interviewing and all the research participants who so generously shared their time with us.

\section{References}

Adams, V., Murphy, M., Clarke, A., 2009. Anticipation: technoscience, life, affect, temporality. Subjectivity 28, 246-265.

Adkins, L., 2011. Practice as temporalisation: Bourdieu and economic crisis. In: Susen, S., Turner, B.S. (Eds.), The Legacy of Pierre Bourdieu: Critical Essays. Anthem Press, London, pp. 347-366.

Anderson, B., 2010. Pre-emption, precaution, preparedness: anticipatory action and future geographies. Prog. Hum. Geogr. 34, 777-798.

Atkinson, W., 2013. Class habitus and perception of the future: recession, employment insecurity and temporality. Br. J. Sociol. 64 (4), 643-662.

Australian Bureau of Statistics, 2013. Census of Population and Housing: Socioeconomic Indexes for Areas (SEIFA), Australia 2011 (2033.0.55.001).

Australian Government National Preventative Health Taskforce, 2009. Obesity in Australia: a Need for Urgent Action. Australian Government. http://www. preventativehealth.org.au/internet/preventativehealth/publishing.nsf/Content/ tech-obesity (last accessed 12.09.14.).

Australian Guide to Healthy Eating, 2014. Australian Government. http://www. eatforhealth.gov.au/guidelines/australian-guide-healthy-eating (last accessed 12.09.14.).

Ball, K., Crawford, D., 2006. Socio-economic factors in obesity: a case of slim chance in a fat world? Asia Pac. J. Clin. Nutr. 15, 15-20.

Barry, C.L., Brescoll, V.L., Brownell, K.D., Schlesinger, M., 2009. Obesity metaphors: how beliefs about the causes of obesity affect support for public policy. Milbank Q. 87, 7-47.

Bauman, Z., 2006. Liquid Fear. Polity Press, Cambridge.

Bauman, Z., 2007. Liquid Times: Living in an Age of Uncertainty. Polity Press, Cambridge.

Beck, U., 1992. Risk Society: Towards a New Modernity. Sage, London.

Berlant, L., 2011. Cruel Optimism. Duke University Press, London.

Bourdieu, P., 1963. The attitude of the Algerian peasant toward time. In: PittRivers, J. (Ed.), Mediterranean Countrymen. Mouton \& Co, Paris, pp. 55-72.

Bourdieu, P., 1977. Outline of a Theory of Practice. Cambridge University Press, Cambridge.

Bourdieu, P., 1979. Algeria 1960. Cambridge University Press, Cambridge.

Bourdieu, P., 1999. The Weight of the World: Social Suffering in Contemporary Society. Polity Press, Cambridge.

Bourdieu, P., 2000. Pascalian Meditations. Polity Press, Cambridge.

Brown, N., Michael, M., 2003. A sociology of expectations: retrospecting prospects and prospecting retrospects. Technol. Anal. Strateg. Manag. 15, 3-18.

Carter, S., Entwistle, V., McCaffery, K., Rychetnik, L., 2011. Shared health governance: the potential danger of oppressive 'healthism'. Am. J. Bioeth. 11 (7), 57-58.

City of Playford, 2004. Youth Issues Paper. http://www.ican.sa.edu.au/files/links/ Playford_Youth_Issues_pap 2.pdf (last accessed 12.09.14.).

Coveney, J., 2008. The government of girth. Health Sociol. Rev. 17, 199-213.

Daniel, T.O., Stanton, C.M., Epstein, L.H., 2013. The future is now. Comparing the effect of episodic future thinking on impulsivity in lean and obese individuals. Appetite 71, 120-125.

Dodghson, R., 2008. In what way is the world really flat? Debates over geographies of the moment. Environ. Plan. D Soc. Space 26, 300-314.

Diprose, R., 2008. Biopolitical technologies of prevention. Health Sociol. Rev. 17, $141-150$.

Evans, B., 2010. Anticipating fatness: childhood, affect and the pre-emptive war on obesity. Trans. Inst. Br. Geogr. 35, 21-38.

Ewald, F., 1991. Insurance and risk. In: Burchell, G., Gordon, C., Miller, P. (Eds.), The Foucault Effect: Studies in Govemmentality. Harvester-Wheatsheaf, Hemel Hempstead, pp. 197-210.

Ezzy, D., 2002. Qualitative Analysis: Practice and Innovation. Allen and Unwin, Australia.

Graham, H., Inskip, H., Francis, B., Harman, J., 2006. Pathways of disadvantage and smoking careers: evidence and policy implications. J. Epidemiol. Community Health 60, ii7-ii12.

Graham, H., 1993. When Life's a Drag: Women, Smoking and Disadvantage. UK Department of Health, London.

Graham, H., 1994. Gender and class as dimensions of smoking behaviour in Britain: insights from a survey of mothers. Soc. Sci. \& Med. 38 (5), 691-698.

Hartwick, C.A., Coveney, J., Cox, D., Meyer, S., Sue, R., 2014. Transferring an innovation in food and lifestyle education: adaptation of a French obesity prevention methodology in Australia (262.2). FASEB J. 28 (1 Suppl. ment), 262.

Hetzel, D., Page, A., Glover, J., Tennant, S., 2004. Inequality in South Australia: Key Determinants of Wellbeing. 1: the Evidence. Department of Health (Government of South Australia), Adelaide.

Hordacre, A.L., Spoehr, J., Crossman, S., Barbaro, B., 2013. City of Playford Sociodemographic, Employment and Education Profile. Australian Workplace Innovation and Social Research Centre, Adelaide.

Jenkins, R., 2002. Pierre Bourdieu. Routledge, London.

Johns, S., 2011. Perceived environmental risk as a predictor of teenage motherhood in a British population. Health \& Place 17, 122-131.

Keane, H., 2006. Time and the female smoker. In: McMahon, E., Olubas, B. (Eds.), Women Making Time: Contemporary Feminist Critique and Cultural Analysis. University of Western Australian Press, Perth, pp. 94-115.

King, L., Grunseit, A., O'Hara, B., Bauman, A., 2013. Evaluating the effectiveness of an Australian obesity mass-media campaign: how did the 'measure-up' campaign measure up in New South Wales? Health Educ. Res. 28 (6), 1029-1039.

Kraftl, P. 2008. Young people, hope and childhood-hope. Space Cult. 11, 81-92.

Kumanyika, S.K., Whitt-Glover, M.C., Gary, T.L., et al., 2007. Expanding the obesity research paradigm to reach African American communities. Prev. Chronic Dis. 4 (4), 1-22. A112.

Kumanyika, S.K., Taylor, W., Lassiter, V., et al., 2012. Community energy balance: a framework for contextualizing cultural influences on high risk of obesity in ethnic minority populations. Prev. Med. 55, 371-381.

Law, I.R., Ward, P.R., Coveney, J., 2011. Food insecurity in South Australian single parents: an assessment of the livelihoods framework approach. Crit. Public Health 21 (4), 455-469.

Lupton, D., 2014. "How do you measure up?" Assumptions about "obesity" and health-related behaviors and beliefs in two Australian "obesity" prevention campaigns. Fat Stud. Interdiscip. J. Body Weight Soc. 3 (1), 32-44.

Massumi, B., 2010. The future birth of the affective fact: the political ontology of threat. In: Gregg, M., Seigworth, G. (Eds.), The Affect Theory Reader. Duke University Press, London, pp. 52-70.

McLennan, A., 2013. An Ethnographic Investigation of Lifestyle Change, Living for the Moment, and Obesity Emergence in Nauru (Unpublished Ph.D. thesis). Oxford University, Institute of Social and Cultural Anthropology.

McLachlan, R., Gilfillan, G., Gordon, J., 2013. Deep and Persistent Disadvantage in Australia. Productivity Commission, Australian Government. http://www.pc. gov.au/_data/assets/pdf_file/0007/124549/deep-persistent-disadvantage.pdf (last accessed 12.09.14.).

McLaren, L., 2007. Socioeconomic status and obesity. Epidemiol. Rev. 29, 29-48.

Nowotny, H., 1994/1989. Time: the Modern and Postmodern Experience. Trans. N. Plaice. Polity Press, Cambridge.

Olds, T., Tomkinson, G., Ferrar, K., Maher, C., 2010. Trends in the prevalence of childhood overweight and obesity in Australian between 1985 and 2008. Int. J. Obes. 34, 57-66.

Parliament of Australia, 2004. Mutual Obligation. http://www.aph.gov.au/About_ Parliament/Parliamentary_Departments/Parliamentary_Library/Publications_ Archive/archive/doleLast (accessed 12.09.14.)

Peel, M., 1995. Good Times, Hard Times: the Past and the Future in Elizabeth. Melbourne University Press, Carlton, Victoria.

Sobal, J., Stunkard, A.J., 1989. Socioeconomic status and obesity: a review of the literature. Psychol. Bull. 105, 260-275.

Spotswood, F., Tapp, A., 2010. Sociocultural change - the key to social marketing success? A case study of increasing exercise in working class communities. Int. J. Health Promot. Educ 48 (2), 52-57.

Susen, S., 2013. Afterword: concluding reflections of the legacy of Pierre Bourdieu. In: Susen, S., Turner, B.S. (Eds.), The Legacy of Pierre Bourdieu: Critical Essays. Anthem Press, London, pp. 367-410.

The University of Adelaide: Population Research and Outcomes Studies (PROS), 2014. Health of South Australian Adults - City of Playford. Technical Report January 2011-December 2013. Commissioned by South Australian Department for Health and Ageing; October 2014.

Warin, M., Gunson, J., 2013. The weight of the word: knowing silences in obesity research. Qual. Health Res. 23 (12), 1686-1696.

Wight, C., 2006. Agents, Structures and International Relations: Politics as Ontology. Cambridge University Press, Cambridge.

Williams, J., Weir, L., 2013. OPAL - the Role of Social Marketing in a Community Based Obesity Prevention Program, vol. 2 (3). Australian Association of Social Marketing. May-June.

Zhang, 1., Rashad, I., 2008. Obesity and time preference: the health consequences of discounting the future. J. Biosoc. Sci. 40, 97-113.

Zivkovic, T., Warin, M., Davies, M., Moore, V., 2010. In the name of the child: the gendered politics of childhood obesity. J. Sociol. 46, 375-392.

Zivkovic, T., Warin, M., Moore, V., Ward, P., Jones, M., 2015. The sweetness of care: biographies, bodies and place. In: Attala, L., Abbotts, E., Lavis, A. (Eds.), Careful Eating: Embodied Entanglements Between Food and Care. Ashgate, Surrey. 